\title{
Improved outcome of haploidentical transplantation in severe aplastic anemia using reduced-intensity fludarabine-based conditioning
}

\author{
Wu Yamei ${ }^{1, *}$, Luo Rongmu ${ }^{2, *}$, Cao Yongbin ${ }^{1}$, Si Yingjian ${ }^{2}$, Li Xiaohong ${ }^{1}$, Zhang \\ Xiaomei ${ }^{2}$, Yan Pei $^{1}$, Du Zhenlan ${ }^{2}$, Wang Haitao ${ }^{1}$, Wang Jing ${ }^{1}$, Wang Bojing ${ }^{1}$, Wu \\ Xiaoxiong ${ }^{1}$ and Da Wanming ${ }^{1,2,3}$ \\ ${ }^{1}$ Department of Hematology, The First Affiliated Hospital, Chinese PLA General Hospital, Beijing 100048, China \\ ${ }^{2}$ Department of Hematology, Affiliated BaYi Children's Hospital, PLA Army General Hospital, Beijing 100700, China \\ ${ }^{3}$ Department of Hematology, Chinese PLA General Hospital, Beijing 100853, China \\ *These authors have contributed equally to this work and should be considered as co-first authors \\ Correspondence to: Da Wanming, email: Dwanming@medmail.com.cn \\ Wu Xiaoxiong, email: xiongwuxiao@sohu.com \\ Keywords: haploidentical, hematopoietic stem cell transplantation, severe aplastic anemia, graft-versus-host disease, graft failure \\ Received: March 13, $2017 \quad$ Accepted: June 19, $2017 \quad$ Published: July 31, 2017 \\ Copyright: Yamei et al. This is an open-access article distributed under the terms of the Creative Commons Attribution License 3.0 \\ (CC BY 3.0), which permits unrestricted use, distribution, and reproduction in any medium, provided the original author and source \\ are credited.
}

\section{ABSTRACT}

Significant improvements in hematopoietic stem cell transplantation (HSCT) with haploidentical family donors (HFD) have confirmed its therapeutic role in severe aplastic anemia (SAA) and led to the evolution of treatment algorithms. However, the optimal conditioning regimen for HFD-HSCT remains undefined, especially the dosage of cyclophosphamide (Cy).

A total of 77 patients with SAA from two research centers, who received HFDHSCT with reduced-intensity fludarabine + cyclophosphamide + thymoglobulin \pm busulfan conditioning regimen plus third-party cells infusion were included in this study, of which 67 pairs had 4-5 loci mismatched. We were particularly interested in whether the dosage of Cy significantly impacted graft failure (GF) and overall survival (OS).

All patients showed sustained hematopoietic engraftment without any increase in severe aGVHD and transplantation-related mortality (TRM). The incidences of grade II-IV aGVHD, grade III-IV aGVHD and extensive cGVHD were $18 \%, 10 \%$ and $7 \%$, respectively. The probabilities of 1 -year and 5 -year OS were $93.1 \%$ and $87.9 \%$, respectively. Furthermore, patient age $<15$ years, MNC cells $>8 \times 10^{8} / \mathrm{kg}$ and donor age $<45$ years were associated with better survival $(P=0.043, P=0.023$, and $P=0.037$, respectively) and engraftment $(P=0.019, P=0.008$, and $P=0.001$, respectively).

Our findings indicated that SAA patients lack MSD benefited the most if HFDHSCT was performed with reduced-intensity fludarabine-based conditioning regimen. Improved outcomes with HFD-HSCT may lead to a salvaged therapy and an expanded direct role for SAA in the future.

\section{INTRODUCTION}

Severe aplastic anemia (SAA) is a rare multi-lineage bone marrow failure and life-threatening disorder, with a high annual incidence of nearly $8 \%$ of all malignant and nonmalignant hematological disorders in China $[1,2]$. Hematopoietic stem cell transplantation (HSCT) from a human leukocyte antigen (HLA)-matched sibling donor (MSD) has become the first-line and gold-standard initial treatment option for younger patients, with long-term 
survival up to $95 \%$ [3-5]. When an MSD is unavailable, intensive immunosuppressive therapy (IST) with horse anti-thymocyte globulin (ATG) and cyclosporine (CSP) is indicated [6]. However, IST has a high failure rate, due to lack of response, relapse and clonal evolution, which was recently demonstrated in two large pediatric series from Europe and Japan that showed a much lower failure-free survival (FFS) following IST than MSD HSCT (37-56\% post-IST versus $83-87 \%$ post-MSD HSCT) $[7,8]$. Treating patients with SAA who lack suitable MSD or matched unrelated donor (MUD) is challenging, particularly those with heavy transfusion and refractory or relapse of IST [9]. Improvements in donor selection, conditioning protocols and supportive care along with advances in understanding disease biology have contributed to increasing success rates of HSCT with alternative donors $[10,11]$.

During the past two decades, alternative donor transplantations using haploidentical family donors (HFD) were suggested to be potential treatments for SAA patients requiring frequent transfusions and repeated IST [12-16]. However, this procedure is limited by a high risk of transplantation-related mortality (TRM), severe high rates of graft rejection (GR), graft-versus-host disease (GVHD) and low overall survival (OS). Recent advances in effective ex vivo depletion of T-cells or unmanipulated in vivo regulation of T-cells, better supportive care, and evolving conditioning regimens have significantly improved the outcome of HFD-HSCT [12-17]. The T-cell antibody, ATG, is critical for in vivo T-cell depletion (TCD). The conditioning regimen of fludarabine (Flu), cyclophosphamide (Cy) and ATG combination (FC/ATG) has been used in patients with SAA not only in MSD transplants but also in alternative donor HSCT [9-14]. However, the optimal conditioning regimen for HFDHSCT remains undefined, especially the dosage of Cy (range: 50-200 mg/kg), which may be associated with TRM, GF and OS. Furthermore, majority of the studies have included either $\leq 30$ cases or single-group with shortterm follow-up, making the results difficult to interpret. Our center had used infusion of umbilical cord tissuederived MSCs (UC-MSCs) as pilot salvage therapy for 21 patients undergoing HFD-HSCT with 2-year OS up to $75 \%$ [13]. Based on our prior successful experiences, we pioneered the reduced-intensity fludarabine-based conditioning with third-party cells infusion for treatment of SAA, especially for patients with heavy transfusion and long-term IST, with the following two features: first, reduction of the dosage of $\mathrm{Cy}$ decreased or alleviated the toxic side-effects, for myeloablative and effective engraftment. Second, third-party donor-derived cells were infused to prevent GVHD and improve the hematoimmunological reconstitution. In the current study, we investigated the long-term feasibility and clinical value of HFD-HSCT with reduced-intensity fludarabine-based regimen plus third-party cells infusion to treat SAA in 77 patients from two research centers.

\section{RESULTS}

\section{Patient and donor characteristics}

Characteristics of patients with HFD-HSCT and donors prior to HSCT are presented in Table 1. Median age of 77 patients and donors were 11 years (range, 1-46 years) and 34 years (range, 11-57 years), respectively. All patients received IST prior to referral to both centers for HFD-HSCT (ATG included; $\mathrm{n}=15$ and ATG excluded; $\mathrm{n}=62)$. Notably, all donors were HLA-mismatched related ( 2 HLA loci mismatched; $n=5 ; 3$ HLA loci mismatched; $n=5 ; 4$ HLA loci mismatched; $n=23$; and 5 HLA loci mismatched; $n=46$ ). Of the total HFD-HSCT, 40 were performed with regimen $\mathrm{A}$ and the remaining 37 with regimen $\mathrm{B}$. The median $\mathrm{MNC}$ dose infused was $10.10 \times 10^{8} / \mathrm{kg}$ (range, $6.30-33.63 \times 10^{8} / \mathrm{kg}$, Table 1), while the median CD34 stem cell dose was $4.77 \times 10^{6} / \mathrm{kg}$ (range, $1.01-17.72 \times 10^{6} / \mathrm{kg}$, Table $\left.1 \mathrm{~A}\right)$.

\section{Engraftment, chimerism and graft failure}

Data for all patients who survived at least 30 days after HSCT and were evaluable for engraftment are summarized in Table 1A. The median time to neutrophil engraftment was 12 days (range, 8-21 days, Table 1). Patients in both groups achieved platelet engraftment in a median of 14 days (range, 9-30 days, Table 1). Two patients in regimen $\mathrm{A}$ and one patient in regimen $\mathrm{B}$ with temporary engraftment after primary graft rejection in regimen A group achieved secondary engraftment and underwent HFD-HSCT with another family donor (Table 2A). Secondary thrombocytopenia occurred in one patient in group $A$ at day +92 . The patient received additional donor lymphocyte infusion (DLI), and was alive and well. All patients achieved full donor chimerism by day +30 after HFD-HSCT.

Comparing the effects of different factors on SAA, GF is depicted in Table 2B. GF was significantly affected by patient age at transplant $(P=0.019)$, donor age $(P$ $=0.001)$, the number of infused MNC cells $(P=0.008)$ and the number of infused CD34+ cells $(P=0.001)$. Moreover, time-to-transplant interval and RBC transfusion before HSCT may be associated with the incidence of GF potency, although not statistically significant $(P=$ 0.081 and $P=0.290$, respectively). However, there was no obviously decreasing tendency toward GF potency in patients with regimen A plus BU $(P=0.667)$.

\section{GVHD}

Grade II-IV acute graft-versus-host disease (aGVHD) occurred in 20 patients $(26 \%)$, of which $\mathrm{n}=11(26 \%)$ were in group A, and $\mathrm{n}=9(26 \%)$ in group $\mathrm{B}$, and grade III-IV aGVHD occurred in eight patients $(10 \%)$, of which $n=5(12 \%)$ were in group $A$ and $n=3$ 
Table 1: Characteristics of 77 patients with severe aplastic anemia (A) and 77 haploidentical donors (B)

A

\begin{tabular}{|c|c|}
\hline Variable & Data \\
\hline Median age at diagnosis $[\mathrm{yr}]$ (range) & $8(1-45)$ \\
\hline \multicolumn{2}{|l|}{ Disease, $n(\%)$} \\
\hline SAA or VSAA & $72(93)$ \\
\hline SAA\&PNH & $5(7)$ \\
\hline \multicolumn{2}{|l|}{ IST prior to referral for HSCT, n(\%) } \\
\hline ATG included & $15(19)$ \\
\hline ATG excluded & $62(81)$ \\
\hline \multicolumn{2}{|l|}{ Transfusion RBC before HSCT, U(\%) } \\
\hline$\geq 25 \mathrm{U}$ & $29(38)$ \\
\hline$<25 \mathrm{U}$ & $48(62)$ \\
\hline Median age at transplant [yr](range) & $11(1-46)$ \\
\hline$\leq 15 \mathrm{yr}, \mathrm{n}(\%)$ & $52(67)$ \\
\hline$>15 \mathrm{yr}, \mathrm{n}(\%)$ & $25(33)$ \\
\hline Median disease duration before HSCT[m](range) & $7(2-182)$ \\
\hline Sex(female/male) & $38 / 39$ \\
\hline \multicolumn{2}{|l|}{ Source of stem cells, $n(\%)$} \\
\hline $\mathrm{BM}+\mathrm{PB}$ & $77(100)$ \\
\hline \multicolumn{2}{|l|}{ Regimen, n(\%) } \\
\hline $\mathrm{A}(\mathrm{Flu}+\mathrm{Cy}+\mathrm{ATG}+\mathrm{Bu})$ & $42(54)$ \\
\hline $\mathrm{B}(\mathrm{Flu}+\mathrm{Cy}+\mathrm{ATG})$ & $35(46)$ \\
\hline Median MNCs, $\times 10^{8} / \mathbf{k g}($ range) & $10.10(6.30-33.63)$ \\
\hline Median CD34+, $\times 10^{6} / \mathrm{kg}$ (range) & $4.77(1.01-17.72)$ \\
\hline \multicolumn{2}{|l|}{ Engraftment, n(\%) } \\
\hline Primary engraftment & $74(96)$ \\
\hline Secondary engraftment & $3(4)$ \\
\hline Median time of ANC $\geq 0.5 \times 10^{9} / \mathrm{L}[\mathrm{d}]($ range $)$ & $12(8-21)$ \\
\hline Median time to PLT $\geq 20 \times 10^{9} / \mathrm{L}[\mathrm{d}]($ range $)$ & $14(9-30)$ \\
\hline \multicolumn{2}{|l|}{ aGVHD, n(\%) } \\
\hline Grades II-IV & $20(26)$ \\
\hline Grade III-IV & $8(10)$ \\
\hline \multicolumn{2}{|l|}{ cGVHD, n(\%) } \\
\hline Limited & $14(18)$ \\
\hline Extensive & $5(7)$ \\
\hline Median follow-up time [m](range) & $20(1-66)$ \\
\hline
\end{tabular}

(Continued) 


\begin{tabular}{|c|c|}
\hline Variable & Data \\
\hline Median age $[y r]($ range) & $34(11-57)$ \\
\hline \multicolumn{2}{|l|}{ D-R sex match, n(\%) } \\
\hline Female to female & $21(28)$ \\
\hline Female to male & $18(23)$ \\
\hline Male to female & $11(14)$ \\
\hline Male to male & $27(35)$ \\
\hline \multicolumn{2}{|c|}{ D-R major blood group match, n(\%) } \\
\hline Match & $43(56)$ \\
\hline Mismatch & $34(44)$ \\
\hline \multicolumn{2}{|l|}{ D-R relationship, $\mathbf{n}(\%)$} \\
\hline Parent-child & $66(86)$ \\
\hline Child to parent & $2(3)$ \\
\hline Siblings & $9(11)$ \\
\hline \multicolumn{2}{|c|}{ D-R HLA-loci mismatched, n(\%) } \\
\hline 2 HLA loci & $4(5)$ \\
\hline 3 HLA loci & $4(5)$ \\
\hline 4 HLA loci & $23(30)$ \\
\hline 5 HLA loci & $46(60)$ \\
\hline
\end{tabular}

D-R, donor-recipient.

$(9 \%)$ in group B. Of these, four patients died, and three progressed to extensive chronic graft-versus-host disease (cGVHD). Collectively, four patients from group $\mathrm{A}$ and one patient from group B developed extensive cGVHD, of which three died. Results of Chi-square statistical analysis with grade III-IV aGVHD and extensive cGVHD as the events of interest are presented in Table 4. Donor-recipient HLA mismatched 5 loci was associated with increased risk of grade III-IV aGVHD occurrence ( $P=0.014$, Table 4$)$. For extensive cGVHD, donor age $\geq 45 \mathrm{yrs}$ and transfusion $\mathrm{RBC} \geq 25 \mathrm{U}$ before HSCT were both significant predictors $(P=0.003$ and $P$ $=0.034$, Table 4).

\section{Transplant-related complications}

As seen in Table 3, toxicity of the reducedintensity conditioning regimen was minimal. Among the 77 patients, only six (8\%) experienced grade III TRT, while none developed grade IV TRT. One patient had grade III TRT in the liver and another patient had grade III TRT in the kidney, which may be associated with oral CSP for more than 15 years. One 5-year-old patient experienced cyclosporine-associated posterior reversible encephalopathy syndrome (CSP-associated PRES) when voriconazole was administered for invasive fungal disease.
In addition, the incidences of hemorrhagic cystitis (HC) and oral ulcers obviously decreased, due to the reduced doses of cyclophosphamide.

In terms of early virus reactivation $(\leq 100 \mathrm{~d})$, viremia occurred in 42 patients $(55 \%)$ and only one patient with secondary HFD-HSCT progressed to CMV-associated interstitial pneumonitis (IPn) after pre-emptive treatment. Epstein-Barr virus (EBV) viremia occurred in 18 patients (23\%), of which one patient developed EBV-associated post-transplant lymphoproliferative disorder (PTLD), and was cured with DLI and rituximab. Out of 74 patients followed up for $>100 \mathrm{~d}$, three developed CMV viremia, one EBV viremia and one PTLD.

Seven patients died after HSCT with a median time of 5 months (range 1-25 months). Overall, seven patients died of severe infections at 1 month, 4 months, 5 months and 17 months (one with septicemia, one with CMVassociated IPn and two with IFD), 3 months for severe aGVHD, 7 months for thrombotic microangiopathy (TMA) and 25 months for bronchiolitis obliterans organizing pneumonitis (BO) after HSCT.

\section{Survival}

During the follow-up for 1-66 months, 70 of the 77 (91\%) patients were alive and well. As shown in Figure 2, 
Table 2: Engraftment

A

\begin{tabular}{|c|c|c|c|}
\hline Patient number & 1 & 31 & 34 \\
\hline Age & 16 & 46 & 20 \\
\hline Diagnosis-to-transplant interval [m] & 50 & 7 & 100 \\
\hline Donor-recipient HLA mismatched & 3 & 4 & 5 \\
\hline Infused MNC cells $\left(8 \times 10^{8} / \mathbf{k g}\right)$ & 7.5 & 7.1 & 8.7 \\
\hline Rejection type & Rej & Rej & Rej \\
\hline Comment & 2 HFD-HSCT & 2 HFD-HSCT & 2 HFD-HSCT \\
\hline Autologous recovery & No & No & No \\
\hline $\operatorname{Alive}(\mathrm{A}) / \operatorname{Death}(\mathrm{D})$, reason & D/CMV-IPn & $\mathbf{A}$ & $\mathbf{A}$ \\
\hline Follow-up [m] & 5 & 18 & 9 \\
\hline Transfusion dependent & - & No & No \\
\hline
\end{tabular}

B

\begin{tabular}{|c|c|c|}
\hline Effects & Event(GF)/total & $p$ value \\
\hline \multicolumn{3}{|l|}{ Patient age at transplant } \\
\hline$<15 \mathrm{yr}$ & $0 / 49$ & 0.019 \\
\hline$\geq 15 \mathrm{yr}$ & $3 / 28$ & \\
\hline \multicolumn{3}{|l|}{ Diagnosis-to-transplant interval } \\
\hline$\leq 6$ months & $0 / 38$ & 0.081 \\
\hline$>6$ months & $3 / 39$ & \\
\hline \multicolumn{3}{|l|}{ IST prior to referral for HSCT } \\
\hline ATG included & $0 / 15$ & 0.385 \\
\hline ATG excluded & $3 / 62$ & \\
\hline \multicolumn{3}{|l|}{ Transfusion RBC before HSCT } \\
\hline$\geq 25 \mathrm{U}$ & $2 / 29$ & 0.290 \\
\hline$<25 \mathrm{U}$ & $1 / 48$ & \\
\hline \multicolumn{3}{|l|}{ Infused MNC cells } \\
\hline$\leq 8 \times 10^{8} / \mathrm{kg}$ & $2 / 11$ & 0.008 \\
\hline$>8 \times 10^{8} / \mathrm{kg}$ & $1 / 66$ & \\
\hline Infused CD34+ cells & & 0.001 \\
\hline$\leq 3 \times 10^{6} / \mathrm{kg}$ & $3 / 14$ & \\
\hline$>3 \times 10^{6} / \mathrm{kg}$ & $0 / 63$ & \\
\hline Conditioning regimen & & 0.667 \\
\hline $\mathrm{A}(\mathrm{Flu}+\mathrm{Cy}+\mathrm{ATG}+\mathrm{Bu})$ & $2 / 42$ & \\
\hline $\mathrm{B}(\mathrm{Flu}+\mathrm{Cy}+\mathrm{ATG})$ & $1 / 35$ & \\
\hline Donor age & & 0.001 \\
\hline$<45 \mathrm{yr}$ & $0 / 65$ & \\
\hline$\geq 45 \mathrm{yr}$ & $3 / 12$ & \\
\hline D-R sex match & & 0.290 \\
\hline Match & $1 / 48$ & \\
\hline Mismatch & $2 / 29$ & \\
\hline D-R major blood group match & & 0.700 \\
\hline Match & $2 / 43$ & \\
\hline Mismatch & $1 / 34$ & \\
\hline D-R HLA mismatched & & 0.341 \\
\hline 2-4 HLA loci & $2 / 31$ & \\
\hline 5 HLA loci & $1 / 46$ & \\
\hline
\end{tabular}

(A) Clinical data and outcome of three patients with GR or GF. (B) Comparison of effects of different variables on GF of patients after transplantation.

GF, graft failure; GR, graft rejection.

D-R, donor-recipient. 
Table 3: Transplantation-related toxicity following HFD-HSCT

\begin{tabular}{lcc}
\hline Variable & Grade I/II, $\mathbf{n}(\%)$ & Grade III/IV, $\mathbf{n}(\%)$ \\
\hline Mucosa & 8 & 2 \\
Bladder & 1 & 0 \\
Kidneys & 2 & 1 \\
Liver & 2 & 1 \\
CNS & 1 & 1 \\
Heart & 1 & 0 \\
GI toxicity & 3 & 1 \\
total & $18(24 \%)$ & $6(8 \%)$ \\
\hline
\end{tabular}

CNS, central nervous system; GI, gastrointestinal.

the probabilities of 1-year, 2-year and 5-year OS were $93.1 \%, 91.0 \%$ and $87.9 \%$ in the 77 patients, respectively. Moreover, the probabilities of 1-year, 2-year and 5-year FFS were $91.5 \%, 87.3 \%$ and $84.3 \%$, respectively. In addition, the 1-year OS rates did not significantly differ between groups A and B (92.3\% versus $93.8 \%, P=0.721$; Figure 1).

Comparing the effects of different factors on SAA, OS is depicted in Table 5 and Figure 1. Chi-square statistical analysis revealed that intervals $>6$ months was a significant predictor of death $(P=0.036)$. Age of patients and donors at transplant was significantly associated with patient outcomes after transplantation. Better outcomes were seen in patients $<15$ years old $(P=0.043)$ and donors $<45$ years old $(P=0.037)$ at transplant than those who were older. Moreover, patient outcomes were also significantly affected by the number of infused MNC cells $(P=0.023)$. Similarly, a significantly increasing tendency toward worse OS was noted in patients who developed grade III-IV aGVHD or extensive cGVHD $(P=0.001$ and $P=0.001$, respectively).

\section{DISCUSSION}

Despite promising evidence for HFD-HSCT in acquired SAA in the last decade, several obstacles remain, such as standardized conditioning regimen, methods to regulate the donor T-cells and decrease GVHD, stem cell source, donor selection, and management of GF or poor graft function, which need to be resolved for widespread use $[23,24]$. In this study, patients with SAA grafted from HFD, who were administered a reduced-intensity fludarabine-based conditioning regimen, with third party cells infusion, showed an encouraging 2-year survival of $91.0 \%$, without decrease in the engraftment potency and increase in incidence of GVHD. The new data in the study has been substantially improved to our publication of Stem Cell Research, and at the same time, which could achieve comparable outcomes with HLA-identical sibling transplantation our center (2-year survival of $93.0 \%$, unpublished data). Furthermore, there were six major risk factors of OS, albeit with no significant repetition in multivariate analysis and this held true for other significant associations with OS and FFS. Indeed, 70 of the 77 (91\%) patients with SAA who received HFD-HSCT had normal full blood counts and the majority had full donor chimerism, indicating complete restoration of normal bone marrow function.

Recently, fludarabine-based conditioning regimens for SAA patients receiving alternative donor HSCT have shown promising results, but the role and dose of $\mathrm{Cy}$ in the combination regimens have not been well established or fully defined [24-28]. The EBMT has shown that FC/ATG may be preferable to the conventional high dose Cy (200 $\mathrm{mg} / \mathrm{kg}$ ) for stable engraftment in SAA patients $>30$ years receiving an HLA-identical graft [25]. However, the EBMT has also shown that FC/ATG could use low dose Cy (1200 $\mathrm{mg} / \mathrm{m}^{2}$, which is approximately equal to $40-50 \mathrm{mg} / \mathrm{kg}$ ) for obviously decreasing TRM in very young patients with SAA receiving MUD-HSCT, of which GF was reported in $16-18 \%$ of the total sample $[24,26]$. Tolar et al. proposed that a Cy dose combined with low-dose TBI should range between 50 and $100 \mathrm{mg} / \mathrm{kg}$ to prevent excessive organ toxicity and GF in MUD-HSCT [28]. Im et al. described 12 patients who underwent T-cell-depleted (TCD) HFD-HSCT after conditioning with Flu $+\mathrm{Cy}(120 \mathrm{mg} / \mathrm{kg})+\mathrm{ATG} \pm \mathrm{TBI}$, where the incidence of GF decreased to 4.8\% [29]. Xu et al. recently reported 101 patients from multiple centers with $4 \%$ incidence of GF and $10 \%$ rate of grade III/IV TRT, who underwent HFD-HSCT after Cy $(200 \mathrm{mg} / \mathrm{kg})+$ ATG protocol with additional $\mathrm{BU}$ [30]. In accordance with these findings and our experience, this study showed that $\mathrm{Cy}$ $100 \mathrm{mg} / \mathrm{kg}$ may be the most optimal dose in combination with Flu + ATG \pm BU for HFD-HSCT for SAA with minimal GF potency (4\%) and grade III/IV toxicity ( $8 \%$ ). Moreover, primary GF caused by immunological resistance 
Table 4: Comparison of effects of different variables on acute and chronic GVHD occurrence after transplantation

\begin{tabular}{|c|c|c|c|c|}
\hline \multirow{2}{*}{ Variable } & \multicolumn{2}{|c|}{ aGVHD (grades III-IV) } & \multicolumn{2}{|c|}{ cGVHD (extensive) } \\
\hline & Event/total & $P$ value & Event/total & $P$ value \\
\hline Patient age at transplant & & 0.944 & & 0.247 \\
\hline$<15 \mathrm{yr}$ & $5 / 49$ & & $2 / 48$ & \\
\hline$\geq 15 \mathrm{yr}$ & $3 / 28$ & & $3 / 27$ & \\
\hline Diagnosis-to-transplant interval & & 0.969 & & 0.291 \\
\hline$\leq 6$ months & $4 / 38$ & & $1 / 38$ & \\
\hline$>6$ months & $4 / 39$ & & $3 / 37$ & \\
\hline Patient sex & & 0.146 & & 0.174 \\
\hline Female & $2 / 38$ & & $1 / 37$ & \\
\hline Male & $6 / 39$ & & $4 / 38$ & \\
\hline IST prior to referral for HSCT & & 0.142 & & 0.738 \\
\hline ATG included & $0 / 15$ & & $1 / 14$ & \\
\hline ATG excluded & $8 / 62$ & & $3 / 61$ & \\
\hline Transfusion RBC before HSCT & & 0.126 & & 0.034 \\
\hline$\geq 25 \mathrm{U}$ & $5 / 29$ & & $4 / 27$ & \\
\hline$<25 \mathrm{U}$ & $3 / 48$ & & $1 / 48$ & \\
\hline Conditioning regimen & & 0.633 & & 0.239 \\
\hline $\mathrm{A}(\mathrm{Flu}+\mathrm{Cy}+\mathrm{ATG}+\mathrm{Bu})$ & $5 / 42$ & & $4 / 41$ & \\
\hline $\mathrm{B}(\mathrm{Flu}+\mathrm{Cy}+\mathrm{ATG})$ & $3 / 35$ & & $1 / 34$ & \\
\hline Time to neutrophil engraftment & & 0.907 & & 0.174 \\
\hline$\geq 12$ days & $4 / 40$ & & $4 / 38$ & \\
\hline$<12$ days & $4 / 37$ & & $1 / 37$ & \\
\hline Time to platelet engraftment & & 0.746 & & 0.456 \\
\hline$\geq 14$ days & $5 / 44$ & & $2 / 42$ & \\
\hline$<14$ days & $3 / 33$ & & $3 / 33$ & \\
\hline Donor age & & 0.438 & & 0.003 \\
\hline$<45 \mathrm{yr}$ & $6 / 65$ & & $2 / 64$ & \\
\hline$\geq 45 \mathrm{yr}$ & $2 / 12$ & & $3 / 11$ & \\
\hline D-R sex match & & 0.992 & & 0.949 \\
\hline Match & $5 / 48$ & & $3 / 46$ & \\
\hline Mismatch & $3 / 29$ & & $2 / 29$ & \\
\hline D-R major blood group match & & 0.689 & & 0.456 \\
\hline Match & $5 / 43$ & & $2 / 42$ & \\
\hline Mismatch & $3 / 34$ & & $3 / 33$ & \\
\hline D-R HLA mismatched & & 0.014 & & 0.316 \\
\hline 2-4 HLA loci & $0 / 31$ & & $1 / 31$ & \\
\hline 5 HLA loci & $8 / 46$ & & $4 / 44$ & \\
\hline
\end{tabular}

D-R, donor-recipient. 

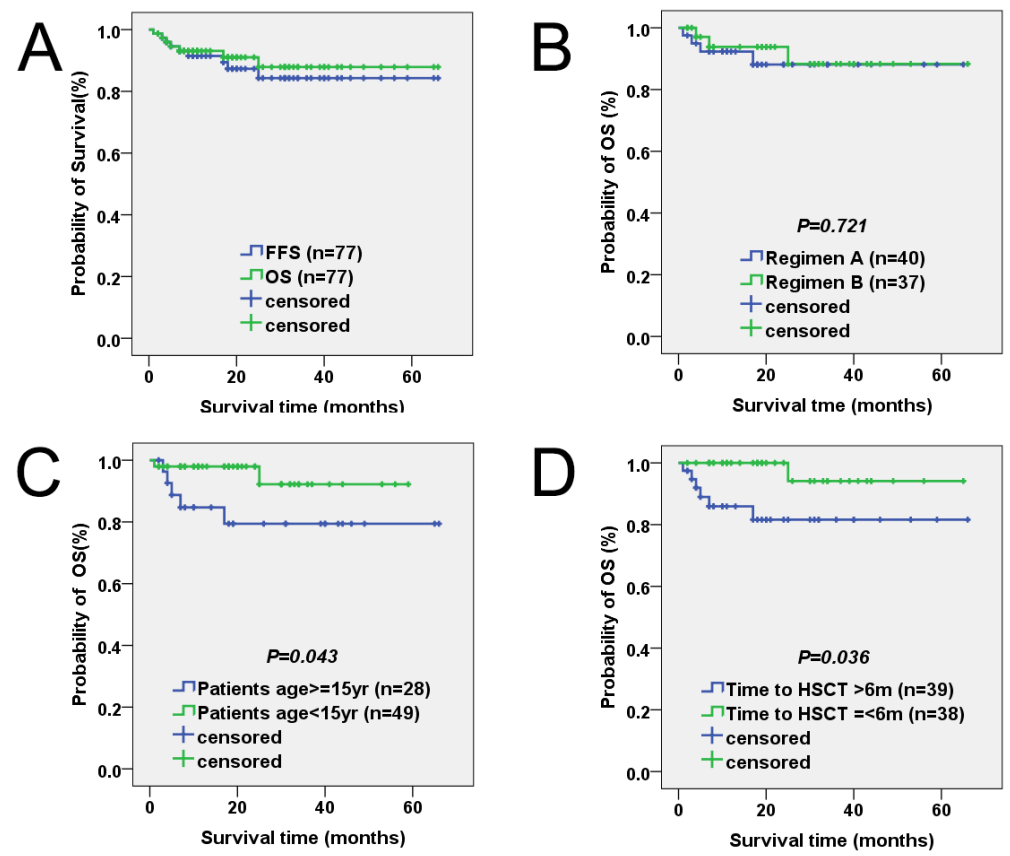

Figure 1: Probability of survival in patients with severe aplastic anemia undergoing HSCT with HFDs. (A) OS and FFS. The probabilities of 1-year OS (green group) and 1-year FFS (blue group) were 93.1\% and 91.5\%, respectively. (B) Survival according to conditioning regimen. The 1-year OS rates between regimen A (blue group) and regimen B (green group) did not significantly differ (92.3\% versus $93.8 \%, p=0.721)$. (C) Survival according to patient age at transplant. The 1 -year OS rates between patients $\geq 15$ years old (blue group) and patients $<15$ years old (green group) was significantly different ( $84.7 \%$ versus $97.9 \%, P=0.043$ ). (D) Survival according to diagnosis-to-transplant interval. Statistical analysis revealed that the 1-year OS rates was obviously different between intervals $>6$ months (blue group) and intervals $\leq 6$ months (green group) $(85.9 \%$ versus $94.1 \%, P=0.036)$.

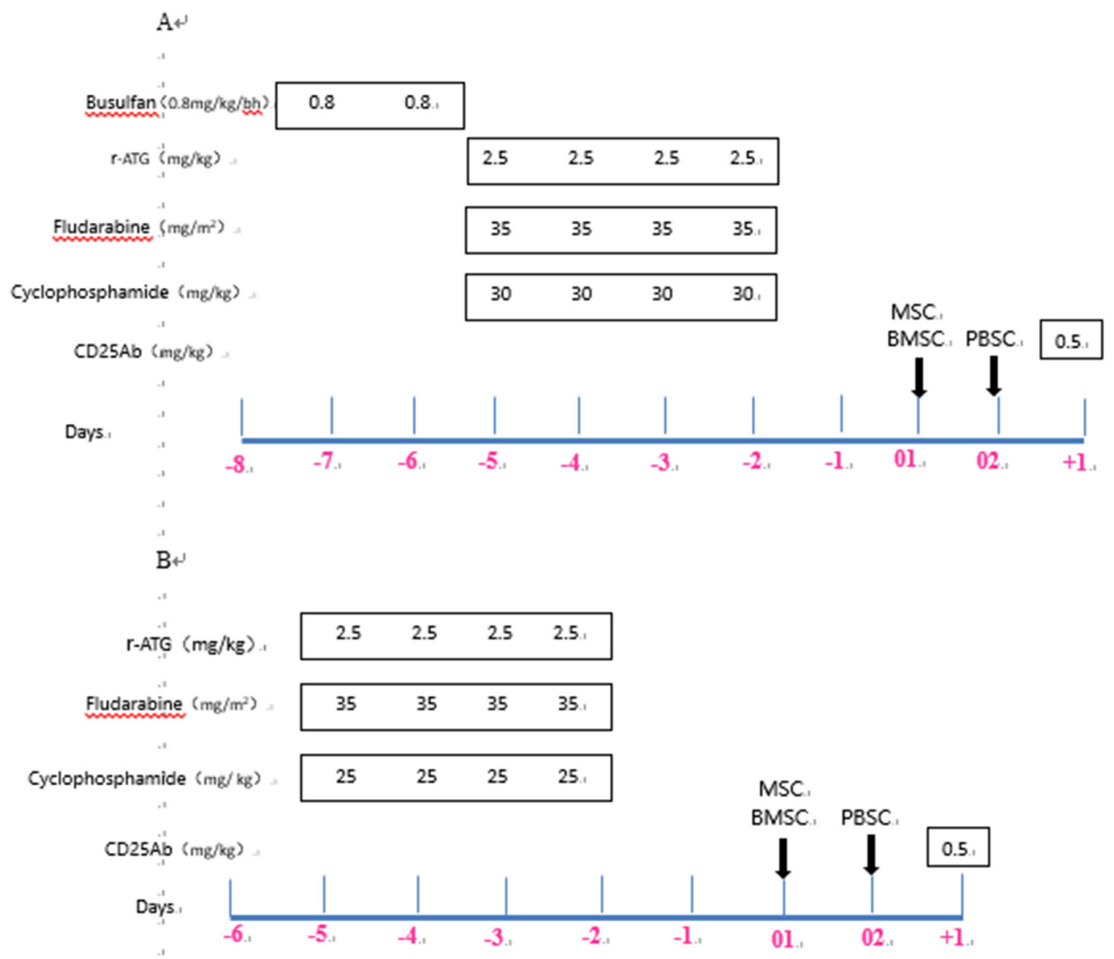

Figure 2: Transplantation protocol for severe aplastic anemia. r-ATG, rabbit anti-thymocyte globulin, Sanofi; r-ATG-F, rabbit anti-thymocyte globulin, Fresenius. (A) Conditioning regimen A for patients with SAA and PNH, or heavy transfusion (RBC $\geq 25 \mathrm{U}$ ), or failed r-ATG therapy. (B) Conditioning regimen B for other patients with SAA or VSAA. 
Table 5: Comparison of effects of different variables on OS of patients after transplantation

\begin{tabular}{|c|c|c|}
\hline Effects & Event(death)/total & $p$ value \\
\hline \multicolumn{3}{|l|}{ Patient age at transplant } \\
\hline$<15 \mathrm{yr}$ & $2 / 49$ & 0.043 \\
\hline$\geq 15 \mathrm{yr}$ & $5 / 28$ & \\
\hline \multicolumn{3}{|l|}{ Diagnosis-to-transplant interval } \\
\hline$\leq 6$ months & $1 / 38$ & 0.036 \\
\hline$>6$ months & $6 / 39$ & \\
\hline Patient sex & & 0.249 \\
\hline Female & $2 / 38$ & \\
\hline Male & $5 / 39$ & \\
\hline \multicolumn{3}{|l|}{ IST prior to referral for HSCT } \\
\hline ATG included & $2 / 15$ & 0.524 \\
\hline ATG excluded & $5 / 62$ & \\
\hline \multicolumn{3}{|l|}{ Transfusion RBC before HSCT } \\
\hline$\geq 25 \mathrm{U}$ & $4 / 29$ & 0.265 \\
\hline$<25 \mathrm{U}$ & $3 / 48$ & \\
\hline \multicolumn{3}{|l|}{ Infused MNC cells } \\
\hline$\leq 8 \times 10^{8} / \mathrm{kg}$ & $3 / 11$ & 0.023 \\
\hline$>8 \times 10^{8} / \mathrm{kg}$ & $4 / 66$ & \\
\hline Infused CD34+ cells & & 0.076 \\
\hline$\leq 3 \times 10^{6} / \mathrm{kg}$ & $3 / 14$ & \\
\hline$>3 \times 10^{6} / \mathrm{kg}$ & $4 / 63$ & \\
\hline Conditioning regimen & & 0.721 \\
\hline $\mathrm{A}(\mathrm{Flu}+\mathrm{Cy}+\mathrm{ATG}+\mathrm{Bu})$ & $4 / 42$ & \\
\hline $\mathrm{B}(\mathrm{Flu}+\mathrm{Cy}+\mathrm{ATG})$ & $3 / 35$ & \\
\hline \multicolumn{3}{|l|}{ Time to neutrophil engraftment } \\
\hline$\geq 12$ days & $4 / 40$ & 0.773 \\
\hline$<12$ days & $3 / 37$ & \\
\hline Time to platelet engraftment & & 0.423 \\
\hline$\geq 14$ days & $5 / 44$ & \\
\hline$<14$ days & $2 / 33$ & \\
\hline aGVHD & & 0.001 \\
\hline No/Grades I-II & $3 / 69$ & \\
\hline Grades III-IV & $4 / 8$ & \\
\hline cGVHD & & 0.001 \\
\hline No/Limited & $4 / 72$ & \\
\hline Extensive & $3 / 5$ & \\
\hline
\end{tabular}

(Continued) 


\begin{tabular}{lcc}
\hline Effects & Event(death)/total & $p$ value \\
\hline Donor age & & $\mathbf{0 . 0 3 7}$ \\
$<45 \mathrm{yr}$ & $4 / 65$ & \\
$\geq 45 \mathrm{yr}$ & $3 / 12$ & 0.684 \\
D-R sex match & & \\
$\quad$ Match & $4 / 48$ & \\
Mismatch & $3 / 29$ & 0.468 \\
D-R major blood group match & & \\
Match & $3 / 43$ & \\
Mismatch & $4 / 34$ & 0.508 \\
D-R HLA mismatched & & \\
2-4 HLA loci & $2 / 31$ & \\
5 HLA loci & $5 / 46$ & \\
\hline
\end{tabular}

D-R, donor-recipient.

to the grafts or inadequate number of progenitors are more common in nonmalignant diseases including SAA, especially heavily transfused cases, than in acute leukemia $[24,31,32]$. For almost $50 \%$ of patients with heavy transfusion in this study, UC-MSCs and high-dose stem cell numbers were both administered to overcome GF and GR. Previous reports have also shown that MSCs could improve engraftment in poor engraftment or graft failure after HSCT $[12,20]$, as well as in patients who previously experienced graft rejection [11, 32]. In the current study, 74 of 77 patients $(96 \%)$ achieved a rapid primary hematopoietic recovery and total full donor chimerism. In addition, the three cases with temporary engraftment after primary GR achieved secondary engraftment underwent HFD-HSCT with another family donor, of which two patients are still alive and well.

HSCT with HFD has been used as a salvage treatment for SAA patients who failed IST, with some encouraging outcome for reducing fatal GVHD in recent studies [12-16]. Numerous approaches have been previously attempted to reduce the incidence of GVHD after HSCT, such as depletion of CD3 cells (or selection of CD34 cells), additional infusion of MSC, intensive prophylactic program for GVHD, and reduced-intensity conditioning regimen. In our study, HFD-HSCT showed similar results to MSD HSCT [2, 8, 23, 33]. Taking MSDHSCT and SAA into consideration, grade III-IV aGVHD, cGVHD and extensive cGVHD rates ranged from $10-20 \%$, $20-44 \%$ and $7-20 \%$, respectively $[2,34-36]$. Based on this study, grade III-IV aGVHD, cGVHD and extensive cGVHD rates were $10 \%, 25 \%$ and $7 \%$, respectively, and comparable to above-cited articles. Grade III-IV aGVHD and extensive cGVHD are lethal forms of GVHD. Grade I-II aGVHD does not frequently cause fatalities and the limited cGVHD effects eventually diminish, so the

patients do not face serious problems, and quality of life post-transplantation is not altered. After reduced-intensity conditioning regimen, the GVHD prophylaxis consisted of CSP, MMF, ATG, CD25Ab and UC-MSCs. Meanwhile, G-CSF-primed bone marrow to the peripheral blood grafts were used, which might contribute to the low incidence of severe GVHD [37]. In our retrospective study, donorrecipient HLA mismatched 5 loci were at greater risk of grade III-IV aGVHD, while donor age $\geq 45$ years and transfusion $\mathrm{RBC} \geq 25 \mathrm{U}$ before HSCT were at greater risk of extensive cGVHD. Similar to OS, GVHD occurrence did not significantly correlate with previous IST treatment $[2,38]$.

The previous barriers to HFD-HSCT, delayed immune reconstitution, severe subsequent infections and TRM are considerably reduced with better supportive care and optimally modified conditioning regimens. The advent of high resolution tissue typing and novel conditioning regimens has significantly reduced the likelihood of these complications. Furthermore, our results suggested that reduced-intensity conditioning regimen might be beneficial for patients with a poor performance score. An additional potential barrier is the time lag between diagnosis and an MSD or MUD HSCT, due to difficulties in finding suitable donors and the time needed to arrange for a donation; which in turn could lead to continuous transfusion, a delay in neutrophil recovery and opportunistic infections [17, 39]. HFD transplantation could be immediately performed without racial or ethnic restrictions because virtually all patients who need HSCT can find a family donor. Furthermore, access to HFD is easier than MUD for cellular therapy to treat infections such as additional DLI for PTLD.

In summary, we found that all major endpoints of allogeneic HSCT for SAA, including engraftment, GVHD, 
life-threatening transplant-related complications, and OS were acceptable. Given the low TRM, stable engraftment and acceptable occurrence of GVHD, reduced-intensity fludarabine-based conditioning with third party cells infusion is considered an established option for patients with SAA by HSCT but lacking suitable MRD or MUD. The finding can potentially change our outlook toward HFD-HSCT for SAA patients, and should encourage further exchange of ideas and experience among transplant specialists. In addition, these findings must be validated by large sample-size, randomized, multi-center and prospective clinical trials.

\section{PATIENTS AND METHODS}

\section{Patients and study design}

This study enrolled 77 consecutive patients with SAA aged 1-46 years (median 9 years), referred to The First Affiliated Hospital of Chinese PLA General Hospital and Affiliated BaYi Children's Hospital, PLA Army General Hospital, who were treated with HFD-HSCT between January 2011 and June 2016. Patients or their legal guardians provided written informed consent for inclusion in the study. The clinical protocol and consent forms were approved by the institutional review board for human investigation at the two research institutions. All procedures described in this study were part of standard care at the two research institutions at the time of treatment.

The patients met the following criteria: (i) diagnosis of SAA, very SAA or SAA and paroxysmal nocturnal hemoglobinuria (PNH) according to the International Aplastic Anemia Study Group [18]; congenital forms of aplastic anemia were excluded; (ii) lack of human leucocyte antigen-MRD or MUD; (iii) no response to previous IST; (iv) absence of any severe pulmonary, cardiac, liver, or renal diseases or active infection; (v) adequate performance status [Eastern Cooperative Oncology Group (ECOG) score 0-2].

\section{Donors and HLA disparity}

Donor-recipient HLA compatibility was predetermined by high-resolution DNA techniques for detecting 10 of 10 alleles, including HLA-A, HLA-B loci, HLA-DRB1, HLA-DQB1 and HLA-C. Donors were ranked based on HLA match, age (younger preferred), gender (same preferred), adaptive binary optimization (ABO) compatibility, and health status (healthy preferred).

\section{Conditioning regimens}

The reduced-intensity fludarabine-based conditioning included one of two regimens: (A) Patients had SAA and PNH, or heavy transfusion (RBC $\geq 25 \mathrm{U}$ ), or failed rabbit ATG (r-ATG, Thymoglobuline, Sanofi, Genzyme Polyclonols S.A.S.) therapy, and received $0.8 \mathrm{mg} / \mathrm{kg} / 6 \mathrm{~h}$ busulfan (days -7 to -6 ), 35 $\mathrm{mg} / \mathrm{m}^{2} /$ day fludarabine (days -5 to -2 ), $25 \mathrm{mg} / \mathrm{kg} /$ day cyclophosphamide (days -5 to -2 ) and $2.5 \mathrm{mg} / \mathrm{kg} /$ day r-ATG (days -5 to -2 ). (B) Other patients with SAA or VSAA received $35 \mathrm{mg} / \mathrm{m}^{2} /$ day fludarabine (days -5 to -2 ), $25 \mathrm{mg} / \mathrm{kg} /$ day cyclophosphamide (days -5 to -2 ), and 2.5 $\mathrm{mg} / \mathrm{kg} /$ day r-ATG (days -5 to -2 ). A graphic representation of the conditioning regimens is shown in Figure 2.

\section{Allogeneic HSC infusion}

Donor bone marrow (BM) and peripheral blood (PB) cells were collected using standard mobilization protocols. Granulocyte colony-stimulating factor (G-CSF, $5 \mu \mathrm{g} / \mathrm{kg} / \mathrm{d}$ for 5 days; Kirin Brewery, Tokyo, Japan) was used to mobilize BM stem cells and PB cells (G-BMPB). $\mathrm{BM}$ cells were harvested to achieve a target mononuclear cell count (MNC) of $2-4 \times 10^{8} / \mathrm{kg}$ of recipient weight. The target MNC from PB was $4-6 \times 10^{8} / \mathrm{kg}$ of recipient weight. BM cells were intravenously infused through a central venous catheter on day 01 , and thawed PB cells were infused on day 02 .

\section{Third-party donor-derived cells infusion}

UC-MSC were used as the third-party donor-derived cells for group A and group B cohorts, respectively. UCMSC were purchased from the National Engineering Research Center of Cell Products, State Key Laboratory of Experimental Hematology. Immunophenotyping of UCMSC was described by Lu et al [19, 20]. The planned UCMSC dosage was $5.0 \times 10^{5}$ cells $/ \mathrm{kg}$ of recipient weight. $\mathrm{BM}$ infusions were performed 4 hours after the completion of UC-MSC infusion [13].

\section{Prophylaxis and treatment of GVHD}

GVHD prophylaxis consisted of intravenous CSP 3 $\mathrm{mg} / \mathrm{kg}$ /day in divided doses beginning on the day before transplantation (day -5) and the target concentration was adjusted to $200-250 \mathrm{ng} / \mathrm{ml}$. Patients were advanced to oral CSP, as tolerated. In the absence of GVHD, the target concentration of CSP was administered for up to 1 year post-HSCT, then tapered and discontinued over the following 3-4 months. The oral MMF dose was 20 $\mathrm{mg} / \mathrm{kg} /$ day from day -3 and was tapered off after 100 days if no aGVHD was observed. CD25Ab (Basiliximab, Novartis Pharma Stein AG, Switzerland) was also intravenously administered at a dose of $0.5 \mathrm{mg} / \mathrm{kg} / \mathrm{day}$ only on day 1 after HSCT. Short-term methotrexate (MTX) was not given for GVHD prophylaxis. Acute and chronic GVHD were treated according to institutional practices. 


\section{Engraftment, toxicity grading, and GVHD grading}

Neutrophil engraftment was defined as the first of three consecutive days in which the neutrophil counts (ANC) exceeded $0.50 \times 10^{9} / \mathrm{L}$, and platelet engraftment was defined as the first of five consecutive days in which the platelet count exceeded $20 \times 10^{9} / \mathrm{L}$ without transfusion. GF was classified as follows: (1) primary non-engraftment (failure to reach ANC of $0.5 \times 10^{9} / \mathrm{L}$ after transplant); (2) rejection (decrease in blood ANC to $<0.5 \times 10^{9} / \mathrm{L}$, after achieving ANC of $0.5 \times 10^{9} / \mathrm{L}$ ); (3) late graft failure (decrease in blood ANC after day 100 to $<1.0 \times 10^{9} / \mathrm{L}$ and platelets to $<30 \times 10^{9} / \mathrm{L}$ ).

The transplantation-related toxicity (TRT) was graded using the National Cancer Institute Common Toxicity Criteria for Adverse Events version 4.0. Time of onset of TRT was defined as toxic effects occurring within 40 days after HSCT. Organ damage due to GVHD or infections were excluded. GVHD was defined according to established criteria [21]. OS was defined as the time from transplantation to death from any cause or the last follow-up. FFS was defined as survival with a response to therapy. Death, GF and relapse were considered as treatment failure. TRM was defined as death without disease progression.

\section{Supportive care and infection prevention}

Antibiotics were empirically administered for fever and neutropenia according to institutional guidelines. G-CSF was routinely administered. Supportive care was provided according to individual institutional practices, and included cytomegalovirus (CMV) infection prophylaxis with ganciclovir and Pneumocystis carinii pneumonia prophylaxis with trimethoprim-sulfamethoxazole [22]. These treatments were administered after ANC exceeded $0.50 \times 10^{\%} / \mathrm{L}$ and continued until immunosuppressive therapy was discontinued. Antifungal prophylaxis included fluconazole, itraconazole, or liposomal amphotericin.

\section{Chimerism analyses}

Chimerism was typically evaluated in recipient BM cells on days $+30,+100,+180$, and +365 after HSCT using cytogenetic G-banding or fluorescence in situ hybridization. Sex-matched donor-recipient chimerism was assessed using PCR-based analyses of polymorphic minisatellite or microsatellite regions. HLA typing was performed for patients with HLA-haploidentical donors.

\section{Statistical analyses}

SPSS 21.0 statistical software was used for all statistical analyses. Patient, disease, and HSCT-related variables were compared between patients with regimens $\mathrm{A}$ and $\mathrm{B}$ using chi-square statistics for categorical variables and the Kruskal-Wallis test for continuous variables. Survival data were analyzed using the log-rank test, and survival curves were plotted using the KaplanMeier method. The incidences of aGVHD and cGVHD were evaluated using the Kaplan-Meier estimate of disease-free survival rates. Differences were considered significant at $P<0.05$.

\section{Author contributions}

$\mathrm{Da} \mathrm{WM}$ and $\mathrm{Wu} \mathrm{XX}$ served as the principal investigator and director over the entire duration of the study. $\mathrm{Wu} \mathrm{YM}$ was the associate investigator, wrote the paper and performed all statistical analyses. $\mathrm{Wu} \mathrm{YM}$ and Luo RM compiled all clinical data. Cao YB, Li XH, Si YJ, Zhang XM, Yan P, Du ZL and Wang HT performed Ward duty as attending doctors. Wang $\mathrm{J}$ was the director of nursing care over the entire study duration. Wang BJ was responsible for the HLA laboratory diagnosis.

\section{ACKNOWLEDGMENTS}

We thank Prof. Suyun Huang (MD Anderson Cancer Center, Houston, TX) for her helpful comments and valuable advice on epidemiological investigation in the paper. This work was supported by Medical Science and Technique Training Foundation for Youths of the Chinese People's Liberation Army (No: 13QNP179).

\section{CONFLICTS OF INTEREST}

The authors declare no conflicts of interest.

\section{REFERENCES}

1. Young NS, Calado RT, Scheinberg P. Current concepts in the pathophysiology and treatment of aplastic anemia. Blood. 2006; 108:2059-19. https://doi.org/10.1182/ blood-2006-03-010777.

2. Hamidieh AA, Mozafari M, Noshad S, Alimoghaddam K, Behfar M, Ghavamzadeh A. Matched related donor hematopotietic stem cell transplantation results in a longterm follow-up of a pediatric acquired severe aplastic anemia subset: a stem cell source perspective. Pediatr Transplant. 2015; 19:399-407. https://doi.org/10.1111/ petr. 12458.

3. Guinan EC. Acquired aplastic anemia in childhood. Hematol Oncol Clin North Am. 2009; 23:171-91. https:// doi.org/10.1016/j.hoc.2009.01.011.

4. Scheinberg P, Young NS. How I treat acquired aplastic anemia. Blood. 2012; 120:1185-96. https://doi.org/10.1182/ blood-2011-12-274019.

5. Kikuchi A, Yabe H, Kato K, Koh K, Inagaki J, Sasahara Y, Suzuki R, Yoshida N, Kudo K, Kobayashi R, Tabuchi K, Kawa K, Kojima S. Long-term outcome of childhood 
aplastic anemia patients who underwent allogenic hematopoietic SCT from an HLA-matched sibling donor in Japan. Bone Marrow Transplant. 2013; 48:657-60. https:// doi.org/10.1038/bmt.2012.205.

6. Scheinberg $\mathrm{P}$, Nunez $\mathrm{O}$, Weinstein B, Scheinberg $\mathrm{P}$, Biancotto A, Wu CO, Young NS. Horse versus rabbit antithymocyte globulin in acquired aplastic anemia. New Engl J Med. 2011; 365:430-8. https://doi.org/10.1056/ NEJMoa1103975.

7. Dufour C, Pillon M, Passweg J, Socié G, Bacigalupo A, Franceschetto G, Carraro E, Oneto R, Risitano AM, Peffault de Latour R, Tichelli A, Rovo A, Peters C, et al. Outcome of aplastic anemia in adolescence: a survey of the Severe Aplastic Anemia Working Party of the European Group for Blood and Marrow Transplantation. Haematologica. 2014; 99:1574-81. https://doi.org/10.3324/haematol.2014.106096.

8. Yoshida N, Kobayashi R, Yabe H, Kosaka Y, Yagasaki H, Watanabe K, Kudo K, Morimoto A, Ohga S, Muramatsu H, Takahashi Y, Kato K, Suzuki R, et al. First-line treatment for severe aplastic anemia in children: bone marrow transplantation from a matched family donor vs. immunosuppressive therapy. Haematologica. 2014; 99:1784-91. https://doi.org/10.3324/haematol.2014.109355.

9. Marsh JC, Ball SE, Cavenagh J, Darbyshire P, Dokal I, Gordon-Smith EC, Keidan J, Laurie A, Martin A, Mercieca J, Killick SB, Stewart R, Yin JA, et al. Guidelines for the diagnosis and management of aplastic anemia. Br J Haematol. 2009; 147:43-70. https://doi. org/10.1111/j.1365-2141.2009.07842.x.

10. Passweg JR, Aljurf M. Treatment and hematopoietic SCT in aplastic anemia. Bone Marrow Transplant. 2013; 48:161. https://doi.org/10.1038/bmt.2012.229.

11. Sangiolo D, Storb R, Deeg HJ, Flowers ME, Martin PJ, Sandmaier BM, Kiem HP, Nash RA, Doney K, Leisenring WM, Georges GE. Outcome of allogeneic hematopoietic cell transplantation from HLA-identical siblings for severe aplastic anemia in patients over 40 years of age. Biol Blood Marrow Transplant. 2010; 16:1411-8. https://doi. org/10.1016/j.bbmt.2010.04.005.

12. Wang Z, Zheng X, Yan H, Li D, Wang H. Good outcome of haploidentical hematopoietic SCT as a salvage therapy in children and adolescents with acquired aplastic anemia. Bone Marrow Transplant. 2014; 49:1481-5. https://doi. org/10.1038/bmt.2014.187.

13. Wu Y, Cao Y, Li X, Xu L, Wang Z, Liu P, Yan P, Liu Z, Wang J, Jiang S, Wu X, Gao C, Da W, et al. Cotransplantation of haploidentical hematopoietic and umbilical cord mesenchymal stem cells for severe aplastic anemia: successful engraftment and mild GVHD. Stem Cell Res. 2014; 12:132-8. https://doi.org/10.1016/j.scr.2013.10.001.

14. Xu LP, Liu KY, Liu DH, Han W, Chen H, Chen YH, Zhang XH, Wang Y, Wang FR, Wang JZ, Huang XJ. A novel protocol for haploidentical hematopoietic SCT without in vitro T-cell depletion in the treatment of severe acquired aplastic anemia. Bone Marrow Transplant. 2012; 47:150712. https://doi.org/10.1038/bmt.2012.79.

15. Esteves I, Bonfim C, Pasquini R, Funke V, Pereira NF, Rocha V, Novis Y, Arrais C, Colturato V, de Souza MP, Torres M, Fernandes JF, Kerbauy FR, et al. Haploidentical BMT and post-transplant CY for severe aplastic anemia: a multicenter retrospective study. Bone Marrow Transplant. 2015; 50:685-9. https://doi.org/10.1038/bmt.2015.20.

16. Gao L, Li Y, Zhang Y, Chen X, Gao L, Zhang C, Liu Y, Kong P, Wang Q, Su Y, Wang C, Wang S, Li B, et al. Longterm outcome of HLA-haploidentical hematopoietic SCT without in vitro T-cell depletion for adult severe aplastic anemia after modified conditioning and supportive therapy. Bone Marrow Transplant. 2014; 49:519-24. https://doi. org/10.1038/bmt.2013.224.

17. Im HJ, Koh KN, Seo JJ. Haploidentical hematopoietic stem cell transplantation in children and adolescents with acquired severe aplastic anemia. Korean J Pediatr. 2015; 58:199-205. https://doi.org/10.3345/kjp.2015.58.6.199.

18. Camitta BM, Thomas ED, Nathan DG, Gale RP, Kopecky KJ, Rappeport JM, Santos G, Gordon-Smith EC, Storb R. A prospective study of androgens and bone marrow transplantation for treatment of severe aplastic anemia. Blood. 1979; 53:504-14.

19. Luo RM, Da WM, Zhang XM, Gale RP, Kopecky KJ, Rappeport JM, Santos G, Gordon-Smith EC, Storb R. Tumorablative haploidentical hematopoietic cell transplantation for treatment of hematologic malignancy in children. Bone Marrow Transplant. 2016; 51:587-8. https:// doi.org/10.1038/bmt.2015.260.

20. Lu LL, Liu YJ, Yang SG, Zhao QJ, Wang X, Gong W, Han ZB, Xu ZS, Lu YX, Liu D, Chen ZZ, Han ZC. Isolation and characterization of human umbilical cord mesenchymal stem cells with hematopoiesis-supportive function and other potentials. Haematologica. 2006; 91:1017-26.

21. Atkinson K, Horowitz MM, Gale RP, Lee MB, Rimm AA, Bortin MM. Consensus among bone marrow transplanters for diagnosis, grading and treatment of chronic graft-versushost disease. Bone Marrow Transplant. 1989; 4:247-54.

22. Goodrich JM, Bowden RA, Fisher L, Keller C, Schoch G, Meyers JD. Ganciclovir prophylaxis to prevent cytomegalovirus disease after allogeneic marrow transplant. Ann Intern Med. 1993; 118:173-8.

23. Al-Zahrani H, Nassar A, Al-Mohareb F, Al-Sharif F, Mohamed S, Al-Anazi K, Patel M, Rasheed W, Saleh AJ, Bakr M, Ahmed S, Ibrahim K, Hussain F, et al. Fludarabine-based conditioning chemotherapy of allogeneic hematopoietic stem cell transplantation in acquired severe aplastic anemia. Biol Blood Marrow Transplant. 2011; 17:717-22. https://doi.org/10.1016/j.bbmt.2010.08.013.

24. Bacigalupo A, Socie' G, Lanino E, Prete A, Locatelli F, Locasciulli A, Cesaro S, Shimoni A, Marsh J, Brune M, Van Lint MT, Oneto R, Passweg J, et al. Fludarabine, cyclophosphamide, antithymocyte globulin, with or without low dose total body irradiation, for alternative 
donor transplants, in acquired severe aplastic anemia: a retrospective study from the EBMT-SAA working party. Haematologica. 2010; 95:976-82. https://doi.org/10.3324/ haematol.2009.018267.

25. Maury S, Bacigalupo A, Anderlini P, Aljurf M, Marsh J, Socié G, Oneto R, Passweg JR. Improved outcome of patients older than 30 years receiving HLA-identical sibling hematopoietic stem cell transplantation for severe acquired aplastic anemia using fludarabine-based conditioning: a comparison with conventional conditioning regimen. Haematologica. 2009; 94:1312-5. https://doi.org/10.3324/ haematol.2009.006916.

26. Bacigalupo A, Locatelli F, Lanino E, Marsh J, Socié G, Maury S, Prete A, Locasciulli A, Cesaro S, Passweg J. Fludarabine, cyclophosphamide and anti-thymocyte globulin for alternative donor transplants in acquired severe aplastic anemia: a report from the EBMT-SAA Working Party. Bone Marrow Transplant. 2005; 36:947-50. https:// doi.org/10.1038/sj.bmt.1705165.

27. Hyoung JK, Kyung TH, Ji WL, Kim H, Park KD, Shin HY, Lee SH, Yoo KH, Sung KW, Koo HH, Lee JW, Chung $\mathrm{NG}$, Cho B, et al. Improved outcome of a reduced toxicityFludarabine, cyclophosphamide plus thymoglobulin conditioning regimen for unrelated donor transplantation in severe aplastic anemia: comparison of 2 multicenter prospective studies. Biol Blood Marrow Transplant. 2016; 22:1455-9. https://doi.org/10.1016/j.bbmt.2016.04.003.

28. Tolar J, Deeg HJ, Arai S, Horwitz M, Antin JH, McCarty JM, Adams RH, Ewell M, Leifer ES, Gersten ID, Carter SL, Horowitz MM, Nakamura R, et al. Fludarabinebased conditioning for marrow transplantation from unrelated donors in severe aplastic anemia:early results of a cyclophosphamide does de-escalation study show lifethreatenting adverse events at predefined cyclophosphamide does levels. Biol Blood Marrow Transplant. 2012; 18:100711. https://doi.org/10.1016/j.bbmt.2012.04.014.

29. Im HJ, Koh KN, Seo JJ. Recent advances in haploidentical hematopoietic stem cell transplantation using ex vivo T celldepleted graft in children and adolescents. Blood Res. 2016; 51:8-16. https://doi.org/10.5045/br.2016.51.1.8.

30. Xu LP, Wang SQ, Wu DP, Wang JM, Gao SJ, Jiang M, Wang CB, Zhang X, Liu QF, Xia LH, Wang X, Huang XJ. Haplo-identical transplantation for acquired severe aplastic anaemia in a multicentre prospective study. Br J Haematol. 2016; 175:265-74. https://doi.org/10.1111/bjh.14225.

31. Park JA, Kon KN, Choi ES, Jang S, Kwon SW, Park CJ, Seo JJ, Im HJ. Successful rescue of early graft failure in pediatric patients using T-cell-depleted haploidentical hematopoietic SCT. Bone Marrow Transplant. 2014; 49:270-5. https://doi.org/10.1038/bmt.2013.163.

32. Lang P, Mueller I, Greil J, Bader P, Schumm M, Pfeiffer M, Bader P, Schumm M, Pfeiffer M, Hoelle W, Klingebiel T, Heinzelmann F, Belka C, et al. Retransplantation with stem cells from mismatched related donors after graft rejection in pediatric patients. Blood Cells Mol Dis. 2008; 40:33-9. https://doi.org/10.1016/j.bcmd.2007.06.027.

33. Kenney-Nasser AA, Leung KS, Mahajan A, Weiss HL, Arce JA, Gottschalk S, Carrum G, Khan SP, Heslop HE, Brenner MK, Bollard CM, Krance RA. Comparable outcomes of matched-related and alternative donor stem cell transplantation for pediatric severe aplastic anemia. Biol Blood Marrow Transplant. 2006; 12:1277-84. https:// doi.org/10.1016/j.bbmt.2006.07.011.

34. Locatelli E, Bruno B, Zecca M, Van-Lint MT, McCann S, Arcese W, Dallorso S, Di Bartolomeo P, Fagioli F, Locasciulli A, Lawler M, Bacigalupo A. Cyclosporin A and short-term methotrexate versus cyclosporin A as graft versus host disease prophylaxis in patients with severe aplastic anemia given allogeneic bone marrow transplantation from an HLA-identical sibling: results of a GITMO/EBMT randomized trial. Blood. 2000; 96:1690-7.

35. Jeong DC, Chung NG, Kang HJ, Koo HH, Kook H, Kim SK, Kim SY, Kim HS, Kim HM, Park KD, Park SK, Park JS, Park JE, et al. Epidemiology and clinical longterm outcome of childhood aplastic anemia in Korea for 15 years: restrospective study of the Korean Society of Pediatric Hematology Oncology (KSPHO). J Pediatr Hematol Oncol. 2011; 33:172-8. https://doi.org/10.1097/ MPH.0b013e31820826a8.

36. Gerull S, Stern M, Apperley J, Beelen D, Brinch L, Bunjes D, Butler A, Ganser A, Ghavamzadeh A, Koh MB, Komarnicki M, Kröger N, Maertens J, et al. Syngeneic transplantation in aplastic anemia: pre-transplant conditioning and peripheral blood are associated with improved engraftment: an observational study on behalf of the Severe Aplastic Anemia and Pediatric Diseases Working Parties of the European Group for Blood and Marrow Transplantation. Haematologica. 2013; 98:1804-9. https:// doi.org/10.3324/haematol.2013.091074.

37. Serody JS, Sparks SD, Lin Y, Capel EJ, Bigelow SH, Kirby SL, Gabriel DA, Wiley JM, Brecher ME, Schell MJ, Folds J, Shea TC. Comparison of granulocyte colonystimulating factor (G-CSF) emobilized peripheral blood progenitor cells and G-CSF estimulated bone marrow as a source of stem cells in HLA-matched sibling transplantation. Biol Blood Marrow Transplant. 2000; 6:434-40.

38. Konopacki J, Porcher R, Robin M, Bieri S, Cayuela JM, Larghero J, Xhaard A, Andreoli AL, Dhedin N, Petropoulou A, Rodriguez-Otero P, Ribaud P, Moins-Teisserenc H, et al. Long-term follow up after allogeneic stem cell transplantation in patients with severe aplastic anemia after cyclophosphamide plus antithymocyte globulin conditioning. Haematologica. 2012; 97:710-6. https://doi. org/10.3324/haematol.2011.050096.

39. Dietz AC, Lucchini G, Samarasinghe S, Pulsipher MA. Evolving hematopoietic stem cell transplantation strategies in severe aplastic anemia. Curr Opin Pediatr. 2016; 28:3-11. https://doi.org/10.1097/MOP.0000000000000299. 